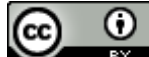

\title{
PSYCHOLOGICAL RESPONSES OF MOTORCAR DRIVERS TO FLASHING AMBER LIGHTS AT SIGNALISED T-INTERSECTIONS
}

\author{
K Galappaththi ${ }^{a *}, O$ K Herath ${ }^{b}, Y M$ Bandara $^{c}$ and M M M Shaja $^{d}$ \\ a IFS R \& D International (Pvt.) Ltd., Colombo, Sri Lanka \\ b, c Department of Transport and Logistics Management, University of Moratuwa, \\ Moratuwa, Sri Lanka \\ d Department of Operations and Logistics, NSBM Green University, \\ Homagama, Sri Lanka \\ * Correspondence should be addressed to kethakag@gmail.com
}

\begin{abstract}
The accurate and timely decision making of drivers is vital to ensuring public safety and reaching the destination in time. This paper presents a detailed comparison of the expectation of regulatory bodies in implementing flashing amber lights and explores the actual driver responses to flashing amber lights at a signalised $T$ intersection by taking speed variation as a proxy for their decision making.

A survey was conducted at a signalised T-intersection during the operation of flashing amber lights to measure the speed variation. Time-distance and speed gun techniques were used to collect speed data of motor cars.

Results reflect those drivers show only a marginal response to flashing amber lights. Therefore, the intention of regulatory bodies that vehicles maintaining lower speed at a T-intersection with flashing amber lights was not satisfactorily fulfilled. The marginal response of drivers to flashing amber lights can be a leading cause of accidents occurring in signalised T-intersections at odd (night) hours.
\end{abstract}

Keywords: Transport Psychology, Driver Behaviour, Driver Utility, Safety, Flashing Amber Light Signalling 


\section{INTRODUCTION}

Passenger transportation plays a vital role in human life and in the economy of a country. Surface transportation mainly consists of public and personalised transport with an operation of a vehicle. Since transport corridors are developed along expressways, highways, and arterial roads, the entire system evolves as a network in which many interactions among modes are inevitable. In such interactions, the decision making of the motor vehicle driver is vital to ensure public safety. Decision making is a cognitive process used by human beings when there are many alternatives to choose in different scenarios [1]. Driver decision making is a research area with a considerable amount of literature. Drivers make decisions on the road in various situations [2]. Some drivers are risk-takers and some others are risk averters [3]. Some decisions are appropriate and avoid accidents while some are inappropriate and lead to accidents of different levels of severity. Unfortunately, some decisions drivers take result in major accidents and fatalities.

People make choices when they select a mode of transport and route; these choices are based on the benefits that they get. Since the decision making of drivers is a cognitive process [1], it may result in a good outcome or an unsafe outcome. There are many factors influencing the decisions, some are internal to the driver (psychology) and some others are external to the driver (external environment such as the behaviour of other drivers and their decisions, the quality of road infrastructure, and traffic signalling and road signs). Relationship between some internal cognitive factors and the decision-making process of drivers has been widely examined in transportation research while assessing the psychological response to such external factors has not been the focus of previous research.

For accident prevention, as a Traffic Demand Management (TDM) strategy, amber lights are flashed at signalised T-intersections to alert motorists to drive cautiously. Flashing amber light is used mostly during night hours with a very low incidence of traffic or when signal cycle timing is dysfunctional. However, this precautionary action has not eliminated T-intersection collisions. During the last decade, there has been a tremendous increase in mobility and motorisation in the country [4]. Road deaths reached a startling total of 3,303 in 2016, while death toll remained high at 3,101 in 2017, at 3097 in 2018, and at 2,829 in 2019 [5]. There were 39,086 accidents reported in 2016, while 18,980 accidents occurred in the first six months of 2017.

A Sri Lankan dies every three and a half hours in road accidents, and the Western Province continues to be the most unsafe region in this respect [4]. During off-peak hours, many T-intersection collisions are reported. The occurrence of accidents at signalised T-intersections during off-peak hours is due to incompatibility between the 
expected and actual reactions of drivers to flashing amber lights or their complete ignorance by the drivers. Hence, the psychological state, decision making, and other behavioural aspects of drivers appear causing increased accidents at T-intersections.

The main objective of this research was to test the effectiveness of flashing amber lights in lowering the speed of vehicles as a measure to prevent collisions at $\mathrm{T}$ intersections during off-peak hours. The study also aimed at recommending a technique for effective accident prevention in off-peak odd (night) hours, if the effectiveness of the flashing amber lights is found unsatisfactory.

\section{LITERATURE REVIEW}

Decision making is a cognitive process of every human being [1]. Many factors influence the decision-making process of humans. Belief in the personal relevance of people [4], age and individual differences [6], cognitive biases [7], and previous experience [3] are some of the factors identified in psychology as influencing the decision-making process [8]. Decisions of drivers or driving behaviours could be defined as the habits of the drivers to choose an option while driving in different kinds of situations [9]. A combination of both good and bad decisions influence behavioural differences among different drivers [10]. Literature has repeatedly examined risky and violent driving behaviours [11]. Consequently, it is proved that risky driving behaviours have larger negative impacts on the safety of road users [10]. It is very useful, therefore, to examine the behaviours of drivers in view of evolving strategies to ensure traffic safety [12].

Several research papers have focused on the decisions of drivers on the road with respect to a range of circumstances. Dinh \& Kubota studied the driver's decision on speed choice and how it is influenced by other drivers. This study analysed the speed choice of drivers [13]. Results indicated that there was a strong relationship between observed speeds and drivers' reported speed, as well as between observed speeds and the intentions to maintain a certain speed [14]. Calisir \& Lehto studied young drivers' decision making on safety and seat belt use. The results indicated that drivers' decision-making process towards the use of safety belts was principally influenced by demographic factors like gender, grade point average and age [15]. Kong, Zhang, \& Chen investigated the young drivers' behaviour with the prediction of the personality, attitudes, and risk perception, mainly focusing on risky decisions of drivers. Results indicated that temperament traits primarily had indirect effects on risk-taking behaviour through their influence on perspective towards traffic safety [16]. Letirand \& Delhomme investigated speed behaviour as a choice between observing and exceeding the speed limits. This research focused on behavioural decisions of drivers pertaining to speeding. Results showed that the performance of 
behaviour and behavioural intention formation were based not on analysis of a single behavioural choice, but on evaluation of many potential choices [17]. Bar-gera \& Shinar studied the intention of passing other vehicles, in other words, the overtaking intention. The results of their experiment indicated that there was a robust tendency for drivers to pass vehicles that travel ahead of them, though these vehicles would be moving faster than their average speed, and therefore, this tendency to overtake explained drivers' speed variability [18]. Nordfjrn, Jrgenson \& Rundmo studied accident association of personality and gender on risky driving behaviour, focusing on both the risky decisions of drivers on the road and how it led to accidents. Its results revealed that risky driving behaviour could be strongly predicted by gender and normlessness [19]. Gelau, Sirek, \& Dahmen-zimmer examined the effects of time pressure on older drivers on left-turn decisions. They found a tendency in the older drivers subject to the survey to require an additional time gap to execute left turns [20]. Zhou, Yu \& Wang analysed mobile phone use while driving. The results supported the effectiveness of the theory of planned behaviour in predicting the first activity intention, which was respondent's intention.

Cestac, Paran \& Delhomme investigated speeding intentions among young drivers. This investigation focused on the decisions of drivers whether to speed up the vehicle or maintain proper speed limits while driving on the road. The results revealed that apparent "friends' behaviour" had an additional influence on the intention to interrupt the rule than apparent "parents' behaviour" had. Ladies were additionally considerably influenced by their feminine friends and boys influenced by their male friends [22]. Atombo, Wu \& Tettehfio studied the motivational factors and unsafe decisions of drivers. This investigation revealed that the theory of planned behaviour corresponding to driver beliefs and to driver behaviour would predict drivers' intentions to rush and overtake to a greater extent than other variables of driver behaviour [23]. Kinnear, Helman, Wallbank, \& Grayson also have undertaken an experimental study of factors associated with driver frustration and overtaking intentions. It has focused on overtaking decisions of drivers which resulted in speed and influenced frustration. The lower speeds were connected with higher self-rated frustration than higher speeds, and drivers' intention to overtake would be higher at lower speeds [24].

In relation to the present research, Wang, Mao, Jin, Wang, \& Guo studied how the drivers take deceleration and acceleration decisions and the human factors influencing such decisions. The results showed that there was a strong relationship between a driver's response time to unexpected events and driving behaviour. Furthermore, risk behaviour of drivers retarded in their response time to unexpected events on the road which leads to accidents [1]. Zhou, Yu \& Wang analysed driver's 
intention on un-signalised cross-intersections in China. The results revealed that straight-moving vehicle drivers from the proper aspect completed their sponge-like selections from 0.9 to 1.3 seconds before reaching the crossing point. However, straight-moving vehicle drivers from the left aspect completed their sponge-like selections from 0.9 to 1.2 seconds before reaching the crossing point [21].

In addition, Kong, Zhang \& Chen examined the intention-aware autonomous driving decision making in an uncontrolled intersection. The study dealt with the kind of decisions that were made by drivers in an uncontrolled intersection. The study proposed a self-directed driving decision making algorithm seeing human-driven vehicle's undefined intentions in an uncontrolled intersection [16]. Similar to the current research, Li, Jia, \& Shao predicted driver behaviour during the yellow interval. The study focused on how the drivers made decisions during the yellow interval and the results indicated that long distance traveling drivers were more likely to make "stop" choices when they approached intersections at the onset of the yellow signal [25]. Williams analysed the kind of decisions the drivers made under the condition of darkness. The results indicated that road traffic fatalities slightly increased during night times even though road traffic crashes significantly decreased at night. The higher fatal crash involvement rates brought evidence to suggest that night-time conditions would pose a greater danger to road users [26].

Previous research showed that drivers made many decisions on the road under different situations, and it is apparent that some decisions were good while some others were bad. Good decisions create a safer environment on the road while bad decisions cause problems to the road users. The studies also indicated that the decisions of the drivers were made in a cognitive process that varied from driver to another and would depend on several factors. It would be useful to analyse the kinds of decisions the drivers would make, and the factors influencing those decisions, in view of creating a safer environment for the drivers. In that respect, utility of driving could be linked with the driver's decision making and could be measured based on travel time, travel cost, safety, convenience, and privacy.

A frequently occurring pattern of accidents was found related to drivers with the right of way confronted by misjudgement of another vehicle crossing their path [27]. Therefore, predicting driver behaviour and assisting drivers in making correct decisions when they approach intersections would help reduce crashes at signalised intersections [25]. A driver assistance system could improve drivers' anticipation of the driving scene. Rittger et al., in agreement with previous research, found that Israeli drivers exhibited great variance in their reaction to the flashing green [28], and thus, flashing-green intervals at the end of the green interval could not be considered as increasing safety at signalised intersections. Warning beacons could be warranted 
at intersections when no conflicting vehicular approaches were faced. Beacons usually flash at a rate of not less than 50 and not more than 60 times per minute. The illuminated period of each flash should not be less than one-half and not more than two-thirds of the total cycle [22]. The response time of the drivers to the effect of amber lights could vary from 0 to 3 seconds [2].

The risk of vehicle crashes at road intersections during amber light operation is high. Relative to $\mathrm{T}$ - Junctions, the fatality risk at $\mathrm{X}$-junction would also be higher during amber lights because of a greater number of approaching lanes and high likelihood of side-impact crashes [29]. Examining the driver behaviour, particularly at an Xjunction, is a task of greater complexity. Even though not directly relevant to this study, machine learning, combined with probabilistic analysis, could be used to develop models pertaining to driver behaviour, which could be of help in evolving strategies to reduce risky driving behaviour [32]. Abuali \& Abou-Zeid proposed a solution to prevent vehicle collisions based on advances of in-vehicle smartphone sensing capabilities and communication, and using recently developed applications in driver behaviour modelling such as cloud-based services [33]. The present research was conducted to examine how drivers psychologically react to flashing amber lights, by assessing speed levels of vehicles passing a T- intersection.

\section{METHODOLOGY}

The methodology used for the study was speed variation measurement. Five locationbased speed levels of vehicles approaching a T-intersection were measured when amber lights were flashing. The measurements were taken to determine speed levels at distances of $25 \mathrm{~m}(\mathrm{D}), 50 \mathrm{~m}$ (C), $75 \mathrm{~m}$ (B) and $125 \mathrm{~m}$ (A) away from the traffic light post, and at the traffic light post (E). The speed of vehicles passing the junction was measured $50 \mathrm{~m}(\mathrm{~F})$ away from the traffic light.

\section{Katubedda Junction}

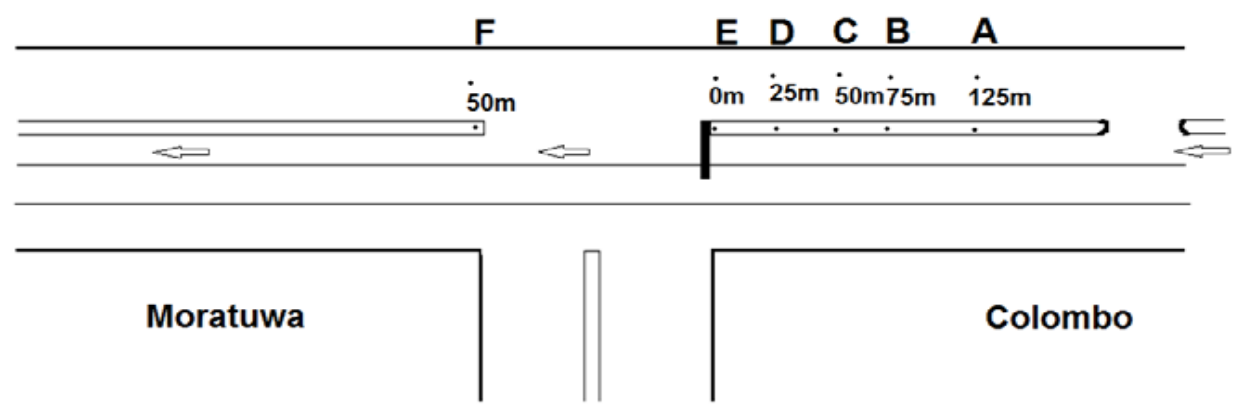

Source: Author compilation

Figure 1: Positions at which the speed levels are measured 
Figure 1 demonstrates the demarcation of survey points at the selected T-intersection (Katubedda Junction, Moratuwa, Sri Lanka). The measurements were taken using the Speed Gun technique and Time-Distance technique. Hence, two types of speed, namely, "time mean speed" and "space mean speed", were captured during the survey. Later, space mean speed also was converted to time mean speed for the purposes of the analysis.

The average speed between any two points was determined by dividing the total distance by elapsed time, as depicted in the Figure 2.

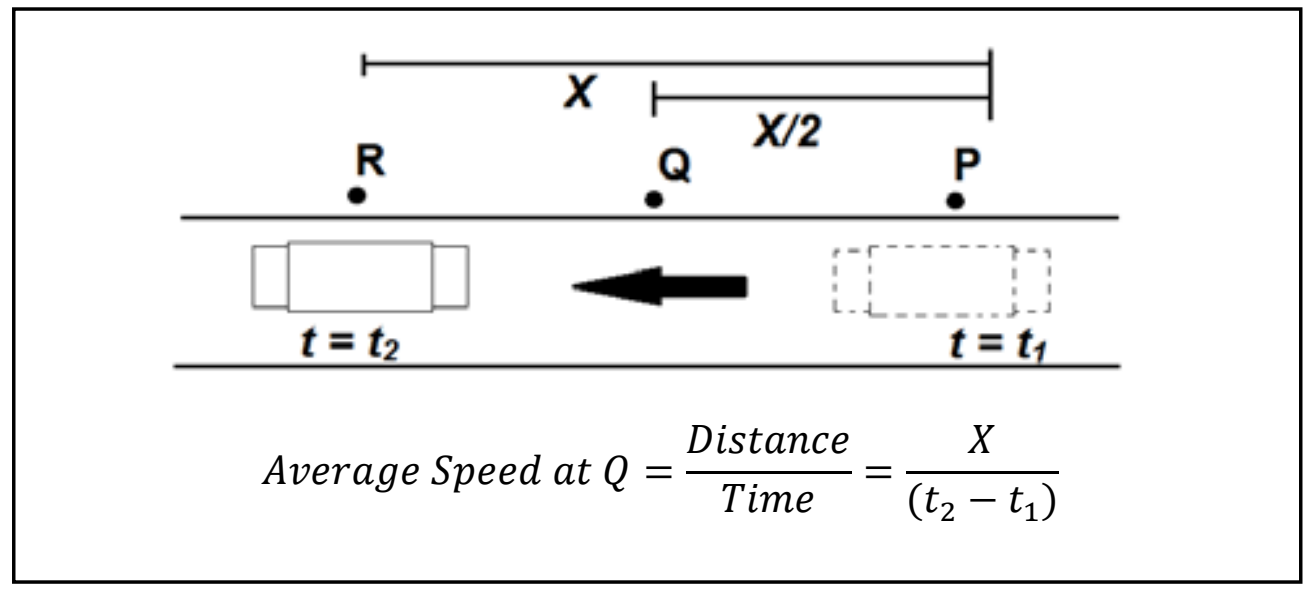

Figure 2: Graphical representation of Time-Distance technique

To determine a single-speed level, time values of two points were needed. A survey for the collection of data was conducted on $22^{\text {nd }}$ March 2018 at Katubedda junction, Moratuwa, Sri Lanka. In the survey, vehicles moving towards Moratuwa direction in the 3rd lane (lane nearest to centre-median) in A2 road (Galle Road) were considered. The north bound traffic data (towards Colombo) were not collected in this survey. Speed variation measurement was implemented as the methodology in the study, as it could act as a proxy to the psychological response of the drivers.

Thus, the psychological response of drivers to flashing amber lights could be assessed. Three ideal situations, as depicted in speed variation graphs in the Figure 3, were expected to be representing the results, namely:

- A minimum point of the speed levels at the colour light position; representing the desirable psychological response for flashing amber lights,

- Constant speed throughout the surveyed distance; representing no psychological response for flashing amber lights,

- A maximum at the colour light position; representing undesired psychological response. 


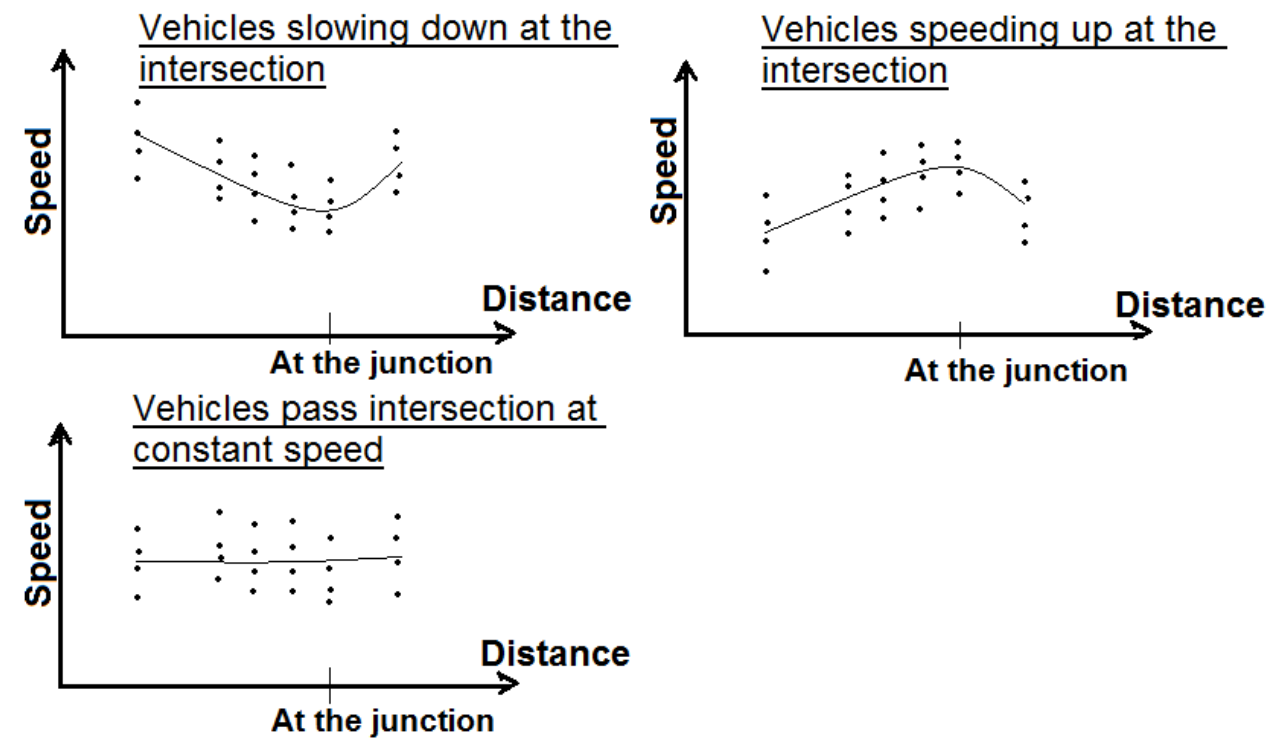

Figure 3: Rough sketches of the possible expected situations

\section{ANALYSIS AND RESULTS}

A total of 758 vehicles were surveyed and the speeds were calculated from the data collected in 3 samples between $10.50 \mathrm{pm}$ to 00.50 am which were grouped into six speed levels. Table 1 summarises minimum, maximum, and average speed levels across all survey points on either side of the T-intersection.

Table 1: Summary of the processed data

\begin{tabular}{|l|c|c|c|c|c|c|}
\hline & A (125m) & B (75m) & C (50m) & D (25m) & E (0m) & F (-50m) \\
\hline Maximum speed (kmph) & 90.0 & 90.0 & 88.0 & 90.0 & 81.0 & 120.0 \\
\hline Minimum speed (kmph) & 25.7 & 20.0 & 19.0 & 22.5 & 19.0 & 20.0 \\
\hline Mean speed (kmph) & 59.2 & 36.5 & 44.8 & 45.4 & 43.2 & 49.1 \\
\hline Standard Deviation & 22.5 & 19.8 & 11.8 & 17.1 & 11.4 & 21.5 \\
\hline Coefficient of Variation & 0.380 & 0.542 & 0.264 & 0.376 & 0.263 & 0.437 \\
\hline
\end{tabular}

Source: Primary data through speed survey

Table 1 presents the various attributes of data at different sections of the signalised T-intersection depicted in Figure 1. The variation of values demonstrates that the actual scenario nearly matches with the expected scenario - vehicle slowing down at the intersection shown in Figure 3. However, different minimum values were reported as vehicles had different speed levels. Therefore, the more meaningful way was to 
analyse the mean speed across the T-intersection. It would give an insight into driver behaviour in terms of vehicle speed and their decision making with respect to risk while crossing the T-intersection. The minimum mean speed was registered $75 \mathrm{~m}$ away from the junction, in contrast to the expectation of observing the minimum mean speed at the junction. However, as expected, maximum mean speeds were registered at the far end of inbound vehicle flow and just after passing the junction. It means that drivers approached and passed T-intersections at free-flowing speed.

Considering solely the maximum speed at each point, it could be deduced that motorcar drivers responded to amber light at signalised T-intersections as intended by the authorities. That was because the minimum value of the maximum speed was recorded at the T-intersection. However, the scatter plot analysis of speed level variations, performed using data gathered through the survey, graphically depicted in Figure 4, indicated a marginal difference of the minimum speed of vehicles occurring before the midpoint of the intersection.

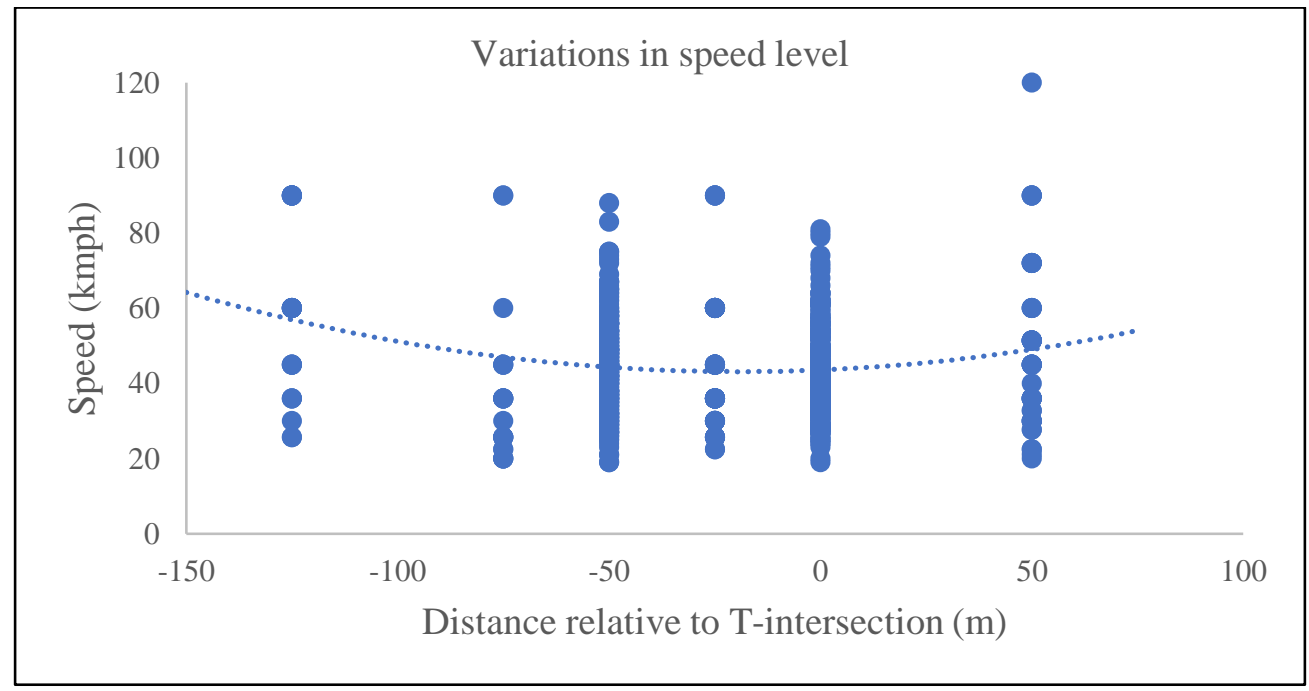

Note: The middle of the junction is at $0 \mathrm{~m}$

\section{Figure 4: Speed level variations of vehicles passing Katubedda junction during amber lights}

In Figure 4, the values of the $\mathrm{x}$-axis represent distances from amber light at which speeds were calculated. Negative values of distances denote the approaching direction of vehicles and positive values denote the passing distances of vehicles from the junction. Only the through traffic at the T-intersection was considered. The impact on the speed of the following-on vehicles towards the T-intersection, from those turning vehicles to the minor road, is negligible because only the inner lane traffic was considered in the analysis. 
The resultant speed variation curve against the distance to the amber light (Figure 4) was a quadratic curve with a "minimum speed" observed 20 metres before the midpoint of the intersection. This implied that the speed reduced when vehicles approached the amber lights at the T-intersection. However, although the speed reduced, the minimum average remained at $40 \mathrm{~km} / \mathrm{hr}$ (maximum recorded was over $50 \mathrm{~km} / \mathrm{hr}$ for more than $1 / 3$ of the vehicles counted). These observations brought suggestive evidence to infer that the drivers would be having a marginal response to flashing amber lights with a higher variance.

This is a serious issue at a T-intersection. It is a questionable behaviour of drivers, as they probably would glance at the incoming traffic towards the T-intersection from crossroads before arriving at the T-intersection and gradually speed up thereafter, if there was no sign of a vehicle approaching or passing through. Hence, drivers would possibly have less ability to react to any sudden vehicle approaching at T-intersections at the time of passing through it under amber light at a speed of 40 to $50 \mathrm{~km}$ per hour. This would also imply that the flow rate on minor roads could have an impact on the speed variations in the major road.

Tay revealed that there was an increased severity of crashes at intersections that occurred during the night-time. Due to the lower traffic density on the roads at night, the motorists showed a greater propensity to speed their vehicles. This behaviour would lead to increase the probability of occurring accidents and their severity [29]. Apart from this, drivers would be unable to respond quickly and effectively at night, because of late-night drowsiness and low visibility. Delay in driver reaction would imply that relatively a shorter time available for a driver to slow down the vehicle, giving rise to increased severity of crashes and fatalities.

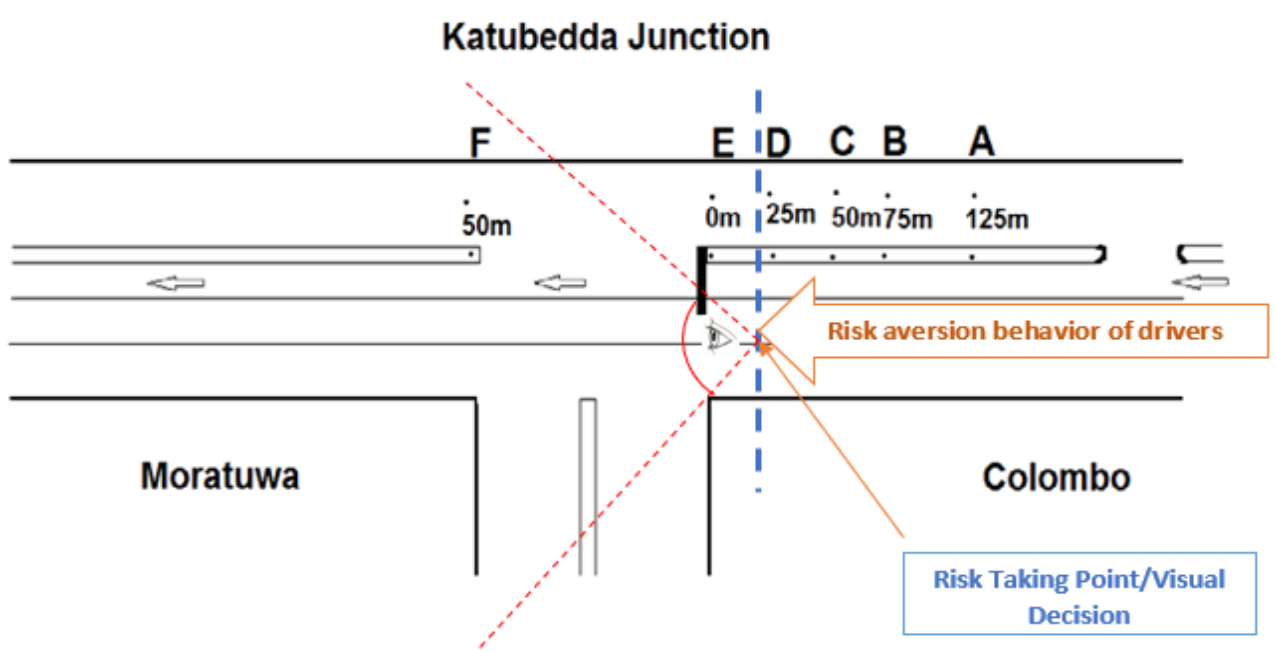

Figure 5: Driving behaviour with distances to amber light 
Based on Figure 5, from $125 \mathrm{~m}$ to $20 \mathrm{~m}$ was the distance where the risk aversion behaviour of drivers was observed. At point $20 \mathrm{~m}$ to the amber light drivers appeared taking the risk after analysing visual observations. This risk-taking point of drivers may vary depending on age, sex, human vision, stress level, and driving condition.

The utility is the level of satisfaction that a human being gets while they make any decisions. People make their choices based on the level of satisfaction that they get from their choices. The utility is the preferences of people that enable them to be represented in numerically useful ways [30]. Driving decisions also would be influenced by the level of satisfaction that the drivers get through driving. Utility matters when the drivers make the decision whether to drive or not and to choose which route to take and which mode to be selected for driving. Schubert evaluated the utility of driving toward automated decision making under uncertainty and the results indicated that the utility of driving could be evaluated toward pre-set decision making under insecurity. The level of utility varies from person to person. The drivers' travel utility maximization model confirms that the drivers display risky behaviour under certain circumstances [31]. The results of the present analysis also confirm the same, that the drivers take a calculated risk. When approaching a Tintersection, they behave differently; one with lower speed but another with relatively higher speeds. A greater variation in speed levels across T-intersections demonstrates the decision making of drivers regarding the speed level and hence their psychological response to amber lights.

\section{CONCLUSIONS AND FUTURE RESEARCH}

From the study, it could be concluded that the expected response of drivers from flashing amber lights was marginally reflected by the speeding behaviour of drivers. Flashing amber lights are implemented to signal drivers to drive with caution. Hence, it is expected that drivers would slow down vehicle speeds at the junction. However, results of the study produced suggestive evidence to infer those drivers would tend to slow down their vehicles before arriving at the T-intersection and accelerate even at the T-intersection.

The difference observed between expectation and responses could be a reason for Tintersection collisions at odd hours. Therefore, the effectiveness of using flashing amber lights as a measure for accident prevention at T-intersections is questionable. The results indicated that the traffic along the main corridor did not proactively respond to the amber light, and as a result, there would be a high chance of collision. Therefore, to mitigate the issue, the traffic light system facing the joining roads should guide and alarm the incoming traffic towards T-intersections. In this regard, system capable of capturing a speedy vehicle approaching towards T-intersection 
along the main corridor and indicating red signal to the vehicle approaching from the joining road, could be recommended.

Implementing a real-time intelligent traffic light system under machine learning concepts could also be recommended as a measure of preventing T-intersection collisions at odd hours. In such a system, the duration of traffic light transitions would change depending on the volume of the traffic passing along each lane, as detected by cameras placed at the junction along each lane. This vision-based decision making could thereafter be converted into a controlled decision-making process. In addition, more space for give-way at $\mathrm{T}$ and $\mathrm{X}$ intersections also could help reduce the impact of collisions during odd hours.

The findings of this study can be used as a steppingstone for further research on driver behaviour for flashing amber lights in signalised intersections. Out of several possible future research areas that can be explored beyond the present study may include investigating driver behaviour with respect to different times of the day, locations, types of intersections. The present research also can be extended to a four-way intersection and compare bi-directional traffic. With that extension, the statistical significance could also be compared. Further research may also focus on measuring the effectiveness of the aforementioned solutions to control traffic at intersections.

\section{ACKNOWLEDGMENTS}

The authors wish to acknowledge the assistance given by the Transport Engineering Division, Department of Civil Engineering for providing speed measurement guns and the Moratuwa Police Station (Traffic OIC), and the surveyors in successfully conducting the traffic survey.

\section{REFERENCES}

[1] W. Wang et al., "Driver's various information process and multi-ruled decision-making mechanism: A fundamental of intelligent driving shaping model," Int. J. Comput. Intell. Syst., vol. 4, no. 3, pp. 297-305, 2011, DOI: 10.1080/18756891.2011.9727786.

[2] J. W. Muttart, "Factors that influence drivers' response choice decisions in video recorded crashes," SAE Tech. Pap., vol. 2005, no. 724, 2005, DOI: 10.4271/2005-01-0426.

[3] W. Breuer, M. Riesener, and A. J. Salzmann, "Risk aversion vs. individualism: what drives risk taking in household finance?," Eur. J. Financ., vol. 20, no. 5, pp. 446-462, 2014, DOI: 10.1080/1351847X.2012.714792. 
[4] Camillus R Abeygoonewardena, "Road safety - a matter of life and death," Road safety - a matter of life and death, 2017. https://www.sundaytimes.lk/ 160228/sunday-times-2/road-safety-a-matter-of-life-and-death-184600.html.

[5] Ministry of Transport, "Road Accidents -The way They are Taking Place," National Council for Road Safety, 2021. [Online]. Available: https://www. transport.gov.lk/web/index.php?option=com_content $\& v i e w=\operatorname{article} \& i d=29 \&$ Itemid=149\&lang=en\#road-accidents.

[6] W. B. De Bruin, A. M. Parker, and B. Fischhoff, "Individual differences in adult decision-making competence," J. Pers. Soc. Psychol., vol. 92, no. 5, pp. 938-956, 2007, DOI: 10.1037/0022-3514.92.5.938.

[7] K. E. Stanovich and R. F. West, "On the Relative Independence of Thinking Biases and Cognitive Ability," J. Pers. Soc. Psychol., vol. 94, no. 4, pp. 672695, 2008, DOI: 10.1037/0022-3514.94.4.672.

[8] C. Dietrich, "Decision Making: Factors that Influence Decision Making, Heuristics Used, and Decision Outcomes," 2010, [Online]. Available: https://www.semanticscholar.org/paper/Decision-Making\%3A-Factors-thatInfluence-Decision-Dietrich/b496716cb15fcd7193aaa7f199ed614b1d7e57fc \#paper-header.

[9] R. Factor, "An empirical analysis of the characteristics of drivers who are ticketed for traffic offences," Transp. Res. Part F Traffic Psychol. Behav., 2018, DOI: 10.1016/j.trf.2017.12.001.

[10] Y. H. Huang et al., "Supervisory interpretation of safety climate versus employee safety climate perception: Association with safety behaviour and outcomes for lone workers," Transp. Res. Part F Traffic Psychol. Behav., vol. 26, no. PB, pp. 348-360, 2014, DOI: 10.1016/j.trf.2014.04.006.

[11] P. B. Harris et al., "The Prosocial and Aggressive Driving Inventory (PADI): A self-report measure of safe and unsafe driving behaviours," Accid. Anal. Prev., vol. 72, no. November, pp. 1-8, 2014, DOI: 10.1016/j.aap.2014.05.023.

[12] P. A. Găianu, C. Giosan, and P. Sârbescu, "From trait anger to aggressive violations in road traffic," Transp. Res. Part F Traffic Psychol. Behav., vol. 70, no. April, pp. 15-24, 2020, DOI: 10.1016/j.trf.2020.02.006.

[13] D. D. Dinh and H. Kubota, "Drivers' perceptions regarding speeding and driving on urban residential streets with a $30 \mathrm{~km} / \mathrm{h}$ speed limit," IATSS Res., vol. 37, no. 1, pp. 30-38, 2013, DOI: 10.1016/j.iatssr.2012.12.001. 
[14] L. Haglund, Mats, Åberg, "Speed choice in relation to speed limit and influences from other drivers," Transp. Res. Part F Traffic Psychol. Behav. Vol. 3, no 1, p. 39-51, vol. 3, pp. 39-51, 2000.

[15] F. Calisir and M. R. Lehto, "Young drivers' decision making and safety belt use," Accid. Anal. Prev., vol. 34, no. 6, pp. 793-805, 2002, DOI: 10.1016/S0001-4575(01)00079-3.

[16] J. Kong, K. Zhang, and X. Chen, "Personality and attitudes as predictors of risky driving behaviour: Evidence from Beijing drivers," Lect. Notes Comput. Sci. (including Subser. Lect. Notes Artif. Intell. Lect. Notes Bioinformatics), vol. 8025 LNCS, PART 1, pp.38-44, 2013, DOI:10.1007/978-3-642-39173-6_5.

[17] F. Letirand and P. Delhomme, "Speed behaviour as a choice between observing and exceeding the speed limit," Transp. Res. Part F Traffic Psychol. Behav., vol. 8, no. 6, pp. 481-492, 2005, DOI: 10.1016/j.trf.2005.06.002.

[18] H. Bar-Gera and D. Shinar, "The tendency of drivers to pass other vehicles," Transp. Res. Part F Traffic Psychol. Behav., vol. 8, no. 6, pp. 429-439, 2005, DOI: 10.1016/j.trf.2005.06.001.

[19] T. Nordfjrn, S. H. Jrgensen, and T. Rundmo, "Safety attitudes, behaviour, anxiety and perceived control among professional and non-professional drivers," J. Risk Res., 2012, DOI: 10.1080/13669877.2012.670132.

[20] C. Gelau, J. Sirek, and K. Dahmen-Zimmer, "Effects of time pressure on leftturn decisions of elderly drivers in a fixed-base driving simulator," Transp. Res. Part F Traffic Psychol. Behav., vol. 14, no. 1, pp. 76-86, 2011, DOI: 10.1016/j.trf.2010.10.002.

[21] R. Zhou, M. Yu, and X. Wang, "Why do drivers use mobile phones while driving? The contribution of compensatory beliefs," PLoS One, vol. 11, no. 8, pp. 3-9, 2016, DOI: 10.1371/journal.pone.0160288.

[22] J. Cestac, F. Paran, and P. Delhomme, "Drive as i say, not as i drive: Influence of injunctive and descriptive norms on speeding intentions among young drivers," Transp. Res. Part F Traffic Psychol. Behav., vol. 23, no. March, pp. 44-56, 2014, DOI: 10.1016/j.trf.2013.12.006.

[23] C. Atombo, C. Wu, E. O. Tettehfio, and A. A. Agbo, "Personality, socioeconomic status, attitude, intention and risky driving behaviour," Cogent Psychol., vol. 4, no. 1, 2017, DOI: 10.1080/23311908.2017.1376424. 
[24] N. Kinnear, S. Helman, C. Wallbank, and G. Grayson, "An experimental study of factors associated with driver frustration and overtaking intentions," Accid. Anal. Prev., vol. 79, pp. 221-230, 2015, DOI: 10.1016/j.aap.2015.03.032.

[25] J. Li, X. Jia, and C. Shao, "Predicting driver behaviour during the yellow interval using video surveillance," Int. J. Environ. Res. Public Health, vol. 13, no. 12, Dec. 2016, DOI: 10.3390/ijerph13121213.

[26] S. B. Williams, "Exploring Driver Behaviour under Conditions of Darkness: Shedding light on the night time traffic death toll," no. December, 2018, [Online]. Available: https://scholar.sun.ac.za.

[27] J. Sandin, "An analysis of common patterns in aggregated causation charts from intersection crashes," Accid. Anal. Prev., vol. 41, no. 3, pp. 624-632, 2009, DOI: 10.1016/j.aap.2009.02.015.

[28] L. Rittger, G. Schmidt, C. Maag, and A. Kiesel, "Driving behaviour at traffic light intersections," Cogn. Technol. Work, vol. 17, no. 4, pp. 593-605, 2015, DOI: 10.1007/s10111-015-0339-x.

[29] R. Tay and S. M. Rifaat, "Factors contributing to the severity of intersection crashes," J. Adv. Transp., vol. 41, no. 3, pp. 245-265, 2007, DOI: 10.1002/atr.5670410303.

[30] H. Schmidli, “Utility Theory," September 2016, pp. 35-46, 2017, DOI: 10.1007/978-3-319-72005-0_2.

[31] R. Schubert, "Evaluating the utility of driving: Toward automated decision making under uncertainty," IEEE Trans. Intell. Transp. Syst., vol. 13, no. 1, pp. 354-364, 2012, DOI: 10.1109/TITS.2011.2171952.

[32] N. O. Alsrehin, A. F. Klaib, and A. Magableh, "Intelligent Transportation and Control Systems Using Data Mining and Machine Learning Techniques: A Comprehensive Study," IEEE Access, vol. 7, 2019, DOI: 10.1109/ACCESS.2019.2909114.

[33] N. Abuali and H. Abou-Zeid, "Driver behaviour modeling: Developments and future directions," International Journal of Vehicular Technology, vol. 2016. 2016, DOI: 10.1155/2016/6952791. 